AIRWAY BIOLOGY

\title{
Phosphodiesterase 4 inhibition decreases MUC5AC expression induced by epidermal growth factor in human airway epithelial cells
}

\author{
M Mata, B Sarriá, A Buenestado, J Cortijo, M Cerdá, E J Morcillo
}

Thorax 2005;60:144-152. doi: 10.1136/thx.2004.025692

See end of article for authors' affiliations

.....................

Correspondence to: Dr E J Morcillo, Department of Pharmacology, Faculty of Medicine, Av. Blasco Ibanez 15, E-46010 Valencia, Spain; Esteban. Morcillo@uv.es

Received 29 March 2004 Accepted

3 November 2004

\begin{abstract}
Background: A common pathological feature of chronic inflammatory airway diseases such as asthma and chronic obstructive pulmonary disease (COPD) is mucus hypersecretion. MUC5AC is the predominant mucin gene expressed in healthy airways and is increased in asthmatic and COPD patients. Recent clinical trials indicate that phosphodiesterase type 4 (PDE4) inhibitors may have therapeutic value for COPD and asthma. However, their direct effects on mucin expression have been scarcely investigated.

Methods: MUC5AC mRNA and protein expression were examined in cultured human airway epithelial cells (A549) and in human isolated bronchial tissue stimulated with epidermal growth factor (EGF; $25 \mathrm{ng}$ / ml). MUC5AC mRNA was measured by real time RT-PCR and MUC5AC protein by ELISA (cell lysates and tissue homogenates), Western blotting (tissue homogenates) and immunohistochemistry.

Results: EGF increased MUC5AC mRNA and protein expression in A549 cells. PDE4 inhibitors produced a concentration dependent inhibition of the EGF induced MUC5AC mRNA and protein expression with potency values $\left(-\log I C_{50}\right)$ : roflumilast $(\sim 7.5)>$ rolipram $(\sim 6.5)>$ cilomilast $(\sim 5.5)$. Roflumilast also inhibited the EGF induced expression of phosphotyrosine proteins, EGF receptor, and phospho-p38- and p44/42-MAPK measured by Western blot analysis in A549 cells. In human isolated bronchus, EGF induced MUC5AC mRNA and protein expression was inhibited by roflumilast $(1 \mu M)$ as well as the MUC5AC positive staining shown by immunohistochemistry.

Conclusion: Selective PDE4 inhibition is effective in decreasing EGF induced MUC5AC expression in human airway epithelial cells. This effect may contribute to the clinical efficacy of this new drug category in mucus hypersecretory diseases.
\end{abstract}

$M$ ucus hypersecretion is an important feature of chronic inflammatory airway diseases such as chronic obstructive pulmonary disease (COPD) and asthma, and contributes to their morbidity and mortality. ${ }^{12}$ MUC5AC is the predominant mucin gene expressed in healthy human airway epithelial cells and its expression is augmented in asthmatic ${ }^{1}$ and COPD patients, ${ }^{3}$ yet MUC5B upregulation is a significant component of airway mucus in asthma ${ }^{4}$ and COPD. ${ }^{5}$ Mucin MUC5AC expression in response to many different stimuli appears regulated by an epidermal growth factor receptor (EGFR) signalling cascade. ${ }^{6}$ Although sparse in healthy adult human airways, EGFR expression is upregulated by proinflammatory cytokines and in chronic airway diseases such as asthma, suggesting that it may have a role in the pathogenesis of mucus hypersecretion in these conditions. ${ }^{17}$

Cyclic AMP (CAMP) is an important second messenger determining many aspects of cellular function through the activation of protein kinase A (PKA). This cyclic nucleotide is inactivated by phosphodiesterases (PDEs). Many distinct forms of PDEs have been described, but PDE4 appears to be the major PDE isoenzyme involved in the regulation of cAMP mediated functions in airway inflammatory and structural cells. ${ }^{8}$ In vitro and in vivo studies have established that selective PDE4 inhibitors suppress the activity of many proinflammatory and immune cells, indicating that they may be effective in the treatment of airway inflammatory diseases. Indeed, oral PDE4 inhibitors are in phase II/III clinical trials for COPD and asthma. ${ }^{8}$ Recent work has shown that rolipram, the archetypal PDE4 inhibitor, markedly decreased goblet cell hyperplasia in animal models of secondary allergen challenge and chronic lipopolysaccharide exposure. $^{910}$ This effect of rolipram was attributed to its known ability to reduce the release of inflammatory mediators which activate goblet cells. However, the direct effects of PDE4 inhibitors on mucin gene expression and production by airway epithelial cells have not so far been investigated to our knowledge.

Normal human airway epithelial cells as well as the human pulmonary epithelial A549 cells predominantly express PDE4 with lesser activity of other PDEs; ${ }^{11}{ }^{12}$ epithelial PDE4 activity may therefore be an important target for monoselective PDE4 inhibitors in the control of those inflammatory mediators produced by these cells. Furthermore, the functioning of the cAMP/PKA pathway appears to be linked to that of the extracellular signal regulated kinase (ERK)/mitogen activated protein kinase (MAPK) pathway, the downstream signalling of the EGFR. ${ }^{13}$

The aim of this study was to examine the effects of PDE4 inhibition on the MUC5AC mucin gene expression and production triggered by the activation of the EGFR with one of its endogenous ligands, the epidermal growth factor (EGF), in cultured human airway epithelial cells (A549 cells) and in human isolated bronchus.

\section{METHODS}

Preparations and chemicals

The human pulmonary epithelial cancer cell line (A549) was purchased from ATCC (American Type Culture Collection; Rockville, MD, USA). This cell line has previously been shown to be appropriate for studies of MUC5AC MRNA and protein expression. ${ }^{14}$ A549 cells were grown on 24-well cultured plates for MUC5AC mRNA experiments or T25 flasks for MUC5AC protein experiments (Corning, NY, USA) 
Table 1 Primers and probes for real time quantitative RT-PCR

\begin{tabular}{|c|c|c|c|c|}
\hline Gene & $\begin{array}{l}\text { Primers and } \\
\text { probes }\end{array}$ & Sequence & $\begin{array}{l}\text { Product size } \\
\text { (bp) }\end{array}$ & $\begin{array}{l}\text { GenBank } \\
\text { accession no }\end{array}$ \\
\hline MUC5AC & $\begin{array}{l}\text { Forward } \\
\text { Reverse } \\
\text { TaqMan probe }\end{array}$ & $\begin{array}{l}\text { 5'-TGTTCTATGAGGGCTGCGTCT-3' } \\
\text { 5'-ATGTCGTGGGACGCACAGA-3' } \\
\text { 5'-TGACCGGTGCCACATGACGGA-3' }\end{array}$ & 102 & U06711 \\
\hline GAPDH & $\begin{array}{l}\text { Forward } \\
\text { Reverse } \\
\text { TaqMan probe }\end{array}$ & $\begin{array}{l}\text { 5'-AGTGGATATTGTTGCCATCA-3' } \\
\text { 5'-GAAGATGGTGATGGGATTTC-3' } \\
\text { 5'-CAAGCTTCCCGTTCTCAGCC-3' }\end{array}$ & 146 & BCO14085 \\
\hline \multicolumn{5}{|c|}{$\begin{array}{l}\text { bp, base pairs. } \\
\text { For MUC5AC, reverse transcription of RNA to generate cDNA was performed with Taqman RT reagents (ref. } \\
\text { N808-0234; Applied Biosystems, NJ, USA) and the PCR was performed with TaqMan Universal PCR Master Mix } \\
\text { (ref. } 4304437 \text {; Applied Biosystems). The specificity of PCR primers was tested under normal PCR conditions and } \\
\text { the products of the reaction were electrophoresed into a } 2.5 \% \text { Nusieve }{ }^{\circledR} \text { GTG }{ }^{\circledR} \text { agarose gel (BMA, Rockland, ME, } \\
\text { USA). One single band with the expected molecular size was observed for MUC5AC and GAPDH. For the } \\
\text { validation of the } \Delta \Delta C_{t} \text { method, the } C_{t} \text { values for target (MUC5AC) and reference (GAPDH) genes were measured } \\
\text { at different input amounts of total RNA ( } 2.34-300 \text { ng); } \Delta C_{t} \text { values (target } v \text { reference) were then plotted against log } \\
\text { total RNA and the absolute value of the slope was found to be } 0.008 \text { (i.e. }<0.1 \text { ), indicating similar efficiency of the } \\
\text { two systems. }\end{array}$} \\
\hline
\end{tabular}

in Roswell Park Memorial Institute (RPMI) 1640 medium containing $10 \%$ endotoxin-free fetal calf serum (FCS), $10 \mathrm{mM}$ HEPES, L-glutamine $(4 \mathrm{mM})$, and standard antimicrobials.

Human lung tissue was obtained from patients (five men, one woman) of mean age 59 years (range 48-69) who had undergone surgery for lung carcinoma as previously outlined..$^{15}$ Experiments were approved by the local ethics committee and informed consent was obtained. At the time of operation all patients were active smokers but lung function was within normal limits by spirometry. None of the patients was being chronically treated with theophylline, $\beta$-adrenoceptor agonists, corticosteroids, or anticholinergic drugs. Bronchial tissue fragments $(\sim 3 \times 3 \mathrm{~mm})$ were placed in a 24-well plate (3-4 fragments per well) with $1 \mathrm{ml}$ RPMI 1640 medium added to each well and left for 30 minutes at $37^{\circ} \mathrm{C}$ before use. A similar preparation has previously been shown to be appropriate for measuring MUC5AC mucin production from goblet cells in the epithelial layer. ${ }^{16}$

Rolipram, cilomilast, and roflumilast were synthesised at Altana Pharma (Konstanz, Germany). Dibutyryl-cAMP, forskolin, and human recombinant epidermal growth factor were from Sigma-Aldrich (Madrid, Spain). H-89, SB202190, PD98059, tyrphostin A46 and AG1478 were from Calbiochem (Nottingham, UK). Sp-5,6-DCl-cBIMPS was from Biolog Life Science Institute (Bremen, Germany). Stock solutions were prepared in water for H89 and dibutyryl-cAMP or in dimethyl sulfoxide (DMSO) for the other compounds except EGF which was reconstituted as a stock solution of $50 \mu \mathrm{g} / \mathrm{ml}$ in $10 \mathrm{mM}$ acetic acid and $0.1 \%$ bovine serum albumin (BSA) as recommended by the supplier. Drugs were further diluted into buffer solutions. The DMSO final concentration in the assay solutions was $0.1 \%(\mathrm{v} / \mathrm{v})$. Water purified on a Milli-Q (Millipore Iberica, Madrid, Spain) system was used throughout.

\section{Experimental protocol}

In preliminary experiments with A549 cells the MUC5AC expression in response to EGF stimulation was determined at $3,12,18$ and 24 hours. Peak responses were observed at 1824 hours for MUC5AC mRNA and at 24 hours for MUC5AC protein; an incubation time of 24 hours was therefore selected in further experiments. Also, $25 \mathrm{ng} / \mathrm{ml}$ EGF was selected as a near maximal response from pilot experiments with EGF (5-50 ng/ml). The selected EGF concentration and time of observation are within the values reported by others in cultured airway epithelial cells. ${ }^{6}{ }^{17} 18$ For human isolated bronchus, MUC5AC responses to EGF stimulation were studied at $0.5,1,3,12$ and 24 hours. In inhibition studies A549 cells and human bronchus were pretreated with drugs or their vehicles for 15 minutes before stimulation with EGF and remained until termination of experiments. When used, antagonists were added 15 minutes before the corresponding drug and remained for the rest of the experiment.

\section{Mucin MUC5AC expression}

The mucin MUC5AC mRNA transcripts were measured by real time quantitative RT-PCR as previously described. ${ }^{19}$ The method used for obtaining quantitative data of relative gene expression, the comparative $C_{t}\left(\Delta \Delta C_{t}\right)$ method, was as described by the manufacturer (PE-ABI PRISM 7700 Sequence Detection System; Perkin-Elmer Applied Biosystems, Perkin-Elmer Corporation, CA, USA). Glyceraldehyde 3-phosphate dehydrogenase (GAPDH) was chosen as the endogenous control gene. Total RNA was extracted using TriPure isolation reagent (Roche, IN, USA). The PCR primers and probes for human MUC5AC and human GAPDH were designed using the Primer Express (PE Biosystems, Morrisville, NC, USA) according to the published human MUC5AC and GAPDH cDNA sequences (table 1).

MUC5AC protein in A549 cells and human bronchial tissues was measured by enzyme linked immunosorbent assay (ELISA) as outlined previously. ${ }^{6}$ In brief, for cell lysates, A549 cells cultured in T25 flasks were trypsinised, washed in PBS, centrifuged $\left(5\right.$ minutes, $\left.300 \mathrm{~g}, 4^{\circ} \mathrm{C}\right)$, and resuspended in five volumes of ice cold lysis buffer ( $50 \mathrm{mM}$ Tris- $\mathrm{HCl}, \mathrm{pH} 7.4$, $1 \%$ SDS, $50 \mathrm{mM} \mathrm{NaCl}, 2 \mathrm{mM}$ EDTA, $1 \mathrm{mM} \mathrm{MgCl}_{2}, 1 \mathrm{mM}$ phenylmethylsulphonyl fluoride (PMSF), $1 \mathrm{mM}$ dithiotreitol (DTT), $2 \mu \mathrm{g} / \mathrm{ml}$ leupeptin, $5 \mu \mathrm{g} / \mathrm{ml}$ aprotinin, $5 \mu \mathrm{g} / \mathrm{ml}$ pepstatin), vortexed for 20 seconds, sonicated, and centrifuged (30 minutes, $13000 \mathrm{~g}, 4^{\circ} \mathrm{C}$ ). Human bronchial tissues were homogenised in five volumes of ice cold lysis buffer $(50 \mathrm{mM}$ Tris- $\mathrm{HCl}, \mathrm{pH} 7.4,1 \mathrm{mM}$ EDTA, $2 \mathrm{mM} \mathrm{MgCl}_{2}, 1 \mathrm{mM}$ phenylmethylsulphonyl fluoride, $1 \mathrm{mM}$ dithiotreitol, $2 \mu \mathrm{g} / \mathrm{ml}$ leupeptin, $5 \mu \mathrm{g} / \mathrm{ml}$ aprotinin, and $5 \mu \mathrm{g} / \mathrm{ml}$ pepstatin) and centrifuged ( 35 minutes, $13000 \mathrm{~g}, 4^{\circ} \mathrm{C}$ ). The total protein in cell and tissue samples was estimated using the Bradford assay..$^{20}$ Samples were stored at $-80^{\circ} \mathrm{C}$.

For ELISA, $100 \mu \mathrm{g}$ total protein was incubated with bicarbonate-carbonate buffer at $40^{\circ} \mathrm{C}$ in a 96 -well plate until dry. Plates were washed with PBS and blocked with $2 \%$ BSA (fraction V; Sigma, St Louis, MO, USA) for 1 hour at room temperature. After three washes, plates were incubated with $50 \mu \mathrm{l}$ mouse monoclonal antibody (mAb) to MUC5AC (clone $45 \mathrm{Ml}$, 1:100; Neomarkers, Fremont, CA, USA; according to the supplier, this $\mathrm{mAb}$ recognises the peptide core of mucin 

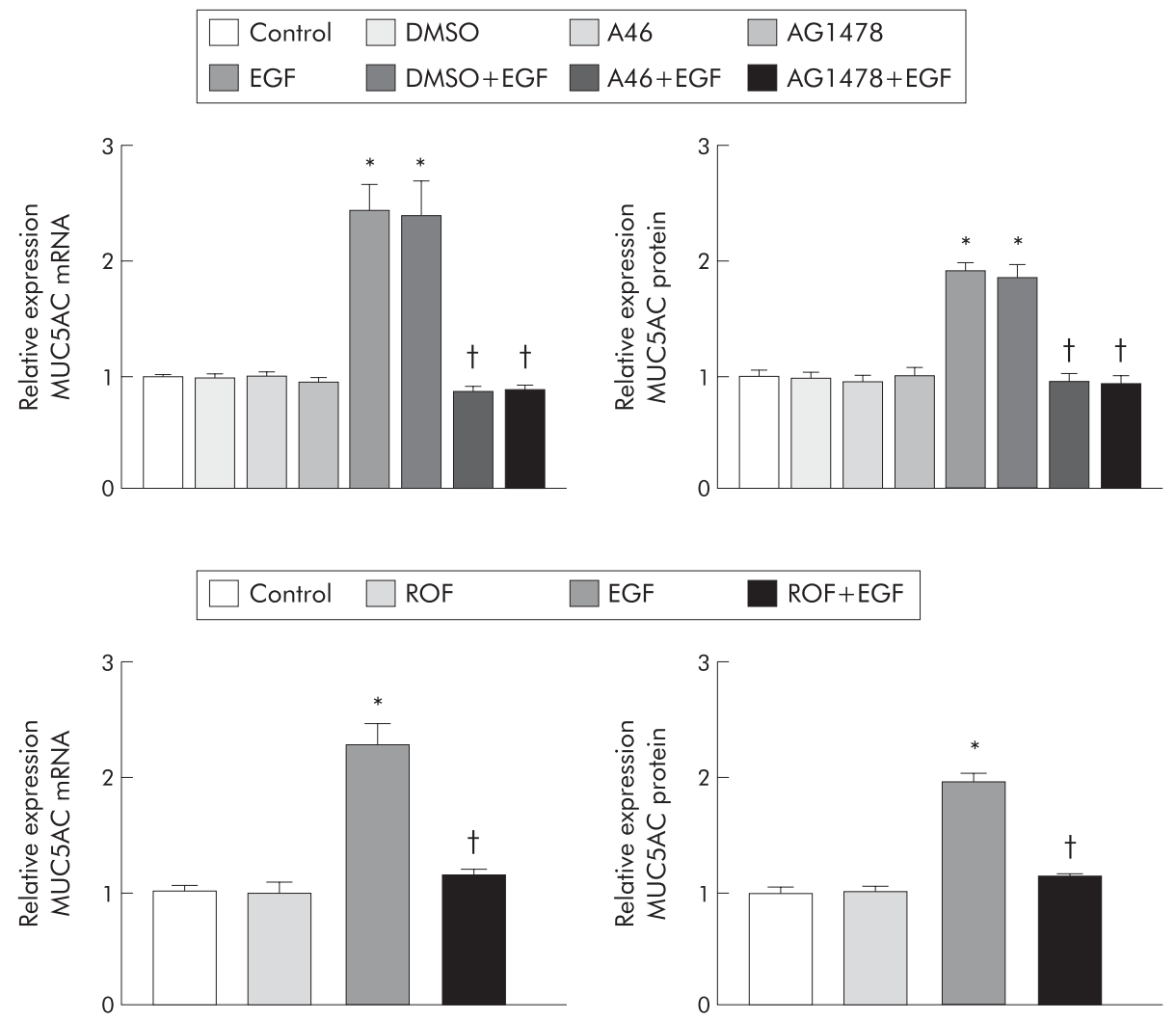

Figure 1 Relative quantitation of MUC5AC mRNA and protein levels in A549 cells unstimulated (control) or stimulated with epidermal growth factor (EGF; $25 \mathrm{ng} / \mathrm{ml}, 24$ hours incubation) in the absence or presence of selective inhibitors of EGF receptor tyrosine kinase activity (tyrphostin A46 and AG1478; upper panels) or a selective phosphodiesterase 4 inhibitor (roflumilast; lower panels). Incubation with DMSO $(0.1 \% \mathrm{v} / \mathrm{v})$ was without significant effect on MUC5AC expression in the absence and presence of EGF (upper panel). The EGF induced increase in MUC5AC expression was abolished by pre-incubation with EGF receptor tyrosine kinase inhibitors (A46 $100 \mu \mathrm{M}$ or AG1478 $3 \mu \mathrm{M}$ ) or roflumilast (1 $\mu \mathrm{M}$ ). MUC5AC mRNA was determined using real time RT-PCR by the $\Delta \Delta C_{t}$ method; columns show the fold increase in expression of MUC5AC relative to GAPDH values as mean (SE) of the $2^{-\Delta \Delta C}$ values of three independent experiments. MUC5AC protein was determined by enzyme linked immunosorbent assay (ELISA); columns show the fold increase from control levels as mean (SE) values of three independent experiments. ${ }^{*} p<0.05 v$ control; $\uparrow p<0.05 v E G F$.

$5 \mathrm{AC}$ and has no cross reactivity with other mucins). After 1 hour the plates were washed with PBS and then incubated with $100 \mu$ horseradish peroxidase-goat anti-mouse IgG conjugated (1:10 000). The colour reaction was developed with TMB peroxidase solution (Sigma) and stopped with $1 \mathrm{M}$ $\mathrm{H}_{2} \mathrm{SO}_{4}$. Absorbance was read at $450 \mathrm{~nm}$.

In addition, Western blot analysis of MUC5AC was carried out in human bronchial homogenates as previously
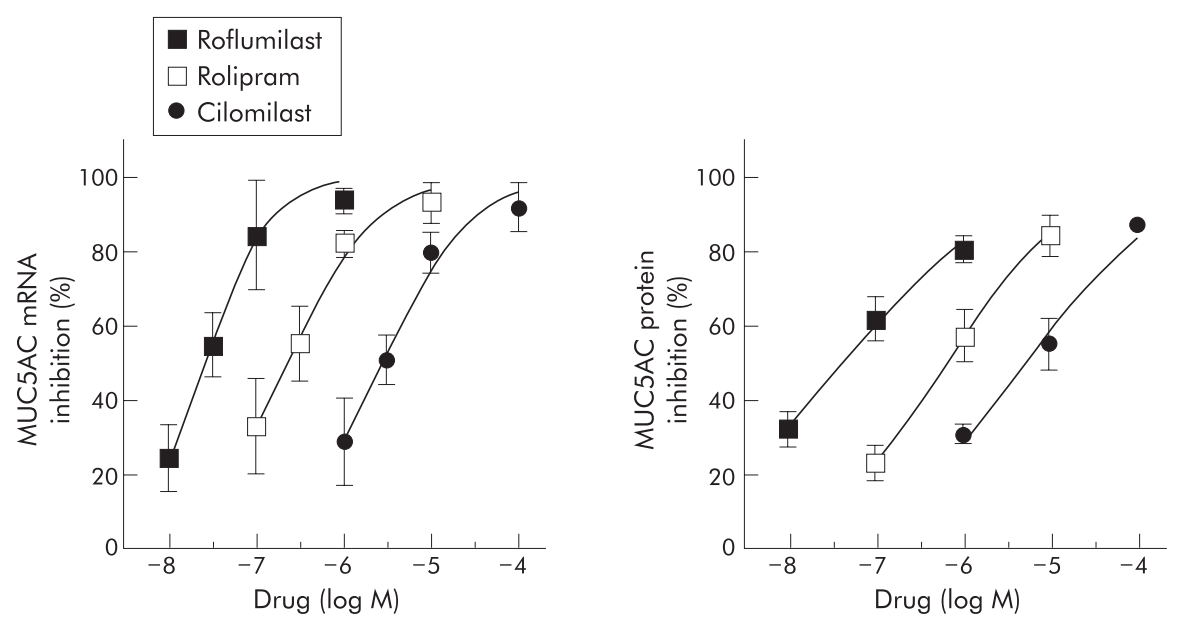

Figure 2 Concentration-response curves for inhibition by the selective PDE4 inhibitors roflumilast, cilomilast and rolipram of the epidermal growth factor ( $25 \mathrm{ng} / \mathrm{ml}$; 24 hours incubation) induced expression of MUC5AC mRNA (left panel) and protein (right panel) in A549 cells. MUC5AC mRNA and protein were determined as indicated in fig 1 . Points are mean (SE) values of three to five independent experiments. The corresponding $I_{50}$ value for each PDE4 inhibitor is shown in the Results section. 
reported. ${ }^{19}$ In brief, aliquots of supernatants from $13000 \mathrm{~g}$ centrifugation of the tissue homogenate containing $25 \mu \mathrm{g}$ total protein were suspended in SDS sample buffer and boiled for 5 minutes. Proteins were separated by SDS-PAGE electrophoresis in $8 \%$ acrylamide-bisacrylamide (80:1). The resulting gel was equilibrated in the transfer buffer: $25 \mathrm{mM}$ Tris- $\mathrm{HCl}, 192 \mathrm{mM}$ glycine, and 20\% (v/v) methanol, $\mathrm{pH} 8.3$. The proteins were then transferred electrophoretically to nitrocellulose membranes which were incubated with $5 \%$ fatfree skimmed milk in phosphate buffered saline (PBS) containing $0.5 \%$ BSA and $0.05 \%$ Tween 20 for 1 hour, and incubated with mAb to MUC5AC (clone 45Ml, 1:500, NeoMarkers) for 2 hours at room temperature. Bound antibody was visualised according to standard protocols for the avidin-biotin-alkaline phosphatase complex method (ABC kit; Vector Laboratories, Burlingame, CA, USA).

For MUC5AC immunocytochemical staining, A549 cells were fixed and stained as previously outlined. ${ }^{17}$ For MUC5AC immunohistochemical analysis of human bronchus, specimens were fixed, cut into sections, stained with haematoxylin-eosin and periodic acid-Schiff (PAS) reagent (to visualise goblet cells), and incubated with mouse monoclonal antibody to MUC5AC (clone 45Ml, 1:100; NeoMarkers, Fremont, CA) as previously reported. ${ }^{1}$

\section{Western blotting of EGFR, phospho-p38 MAPK, phospho-p44/42 MAPK and phosphotyrosine}

A549 cells were prepared for Western blot analysis as indicated above, and preparations were incubated with either EGFR mouse mAb (Ab-12, cocktail R19/48, Neomarkers, CA, USA), phospho-p38 MAPK (Thrl80/Tyr182) mAb (28B10; Cell Signaling Technology, Beverly, MA, USA), phospho-p44/ 42 MAPK (Thr202/Tyr204) mAb (20G11; Cell Signaling Technology), or anti-phosphotyrosine mAb (clone PY20; ICN Biomedical Inc, Aurora, OH, USA) according to the manufacturers' instructions. Expression of EGFR and phosphotyrosine was measured at 24 hours and expression of phospho-p38 MAPK and phospho-p44/42 MAPK at 5, 15, 30 and 60 minutes of EGF $(25 \mathrm{ng} / \mathrm{ml})$ exposure. According to

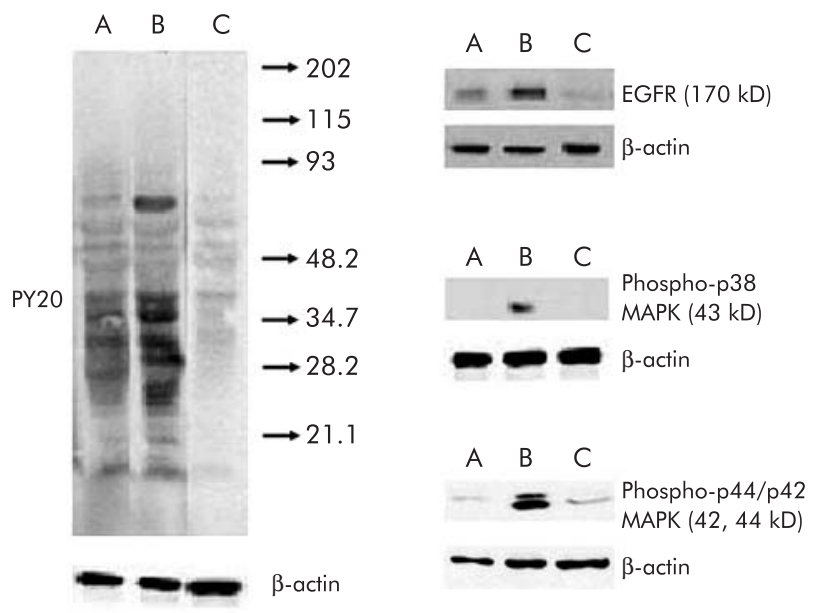

Figure 3 Western analysis of the cellular proteins with PY20 antiphosphotyrosine antibody, anti-EGFR antibody, and phospho-p38 and phospho-p44/42 MAPK antibodies in A549 cell lysates as indicated. Control levels are shown in lane $A$ and the activation produced by EGF $(25 \mathrm{ng} / \mathrm{ml})$ is shown in lane B. Pretreatment with roflumilast (1 $\mu \mathrm{M}$; lane C) reduced the EGF induced response. The duration of EGF exposure was 24 hours for anti-phosphotyrosine and EGFR experiments and 15 minutes for phospho-p38 and phospho-p44/42 MAPK experiments. Data presented are representative of three separate experiments.

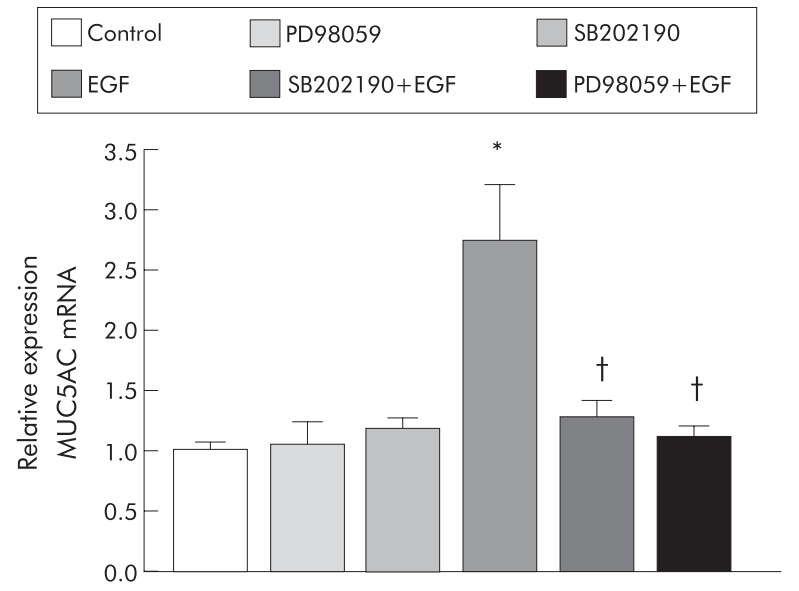

Figure 4 Relative quantitation of MUC5AC mRNA in A549 cells unstimulated (control) or stimulated with epidermal growth factor (EGF; $25 \mathrm{ng} / \mathrm{ml}, 24$ hours incubation) in the absence or presence of selective inhibitors of p38-MAPK activity (SB202190) and p44/42 MAPK (PD98059). The EGF induced increase in MUC5AC expression was abolished by pre-incubation with SB202190 (3 $\mu \mathrm{M})$ or PD98059 $(10 \mu \mathrm{M})$. MUC5AC mRNA was determined using real time RT-PCR by the $\Delta \Delta C_{t}$ method; columns show the fold increase in expression of MUC5AC relative to GAPDH values as mean (SE) of the $2^{-\Delta \Delta C t}$ values of three independent experiments; columns show the fold increase from control levels as mean (SE) values of three independent experiments. ${ }^{*} \mathrm{p}<0.05 v$ control; $\mathrm{tp}<0.05 v$ EGF.

the supplier information, these mAbs are highly selective and do not appreciably cross react with the corresponding confounding targets.

\section{Measurement of cAMP accumulation}

Formation of cAMP was measured as previously outlined. ${ }^{21}$ Cultured A549 cells were exposed to EGF or vehicle in the absence or presence of roflumilast for the indicated times, and the cAMP content was quantified using an enzyme immunoassay kit according to the assay protocol provided by the manufacturer (RPN225; Amersham Life Sciences, UK).

\section{Cytotoxicity assessment}

To exclude the presence of non-selective detrimental effects of the compounds studied, the percentage of lactate

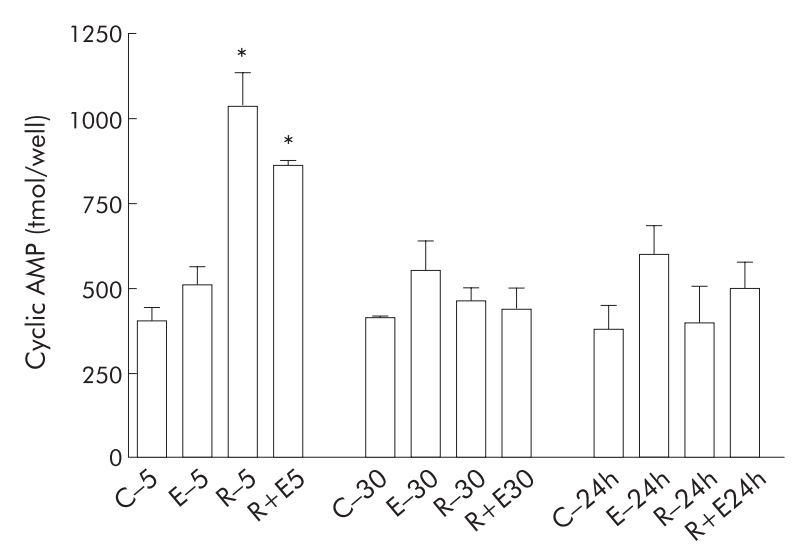

Figure 5 Cyclic AMP levels in A549 cells exposed to EGF (E, $25 \mathrm{ng} / \mathrm{ml})$ for different times ( 5 minutes, 30 minutes and 24 hours, as indicated) in the absence (control, C) or presence of roflumilast $(R, 1 \mu \mathrm{M})$. A significant increase was detected for roflumilast alone and in the presence of EGF only at 5 minutes. Columns are mean (SE) of three to five independent experiments. ${ }^{*} \mathrm{p}<0.05$ from $\mathrm{C}$ and $\mathrm{E}$. 
dehydrogenase (LDH) release was assessed using a commercially available colorimetric assay (Sigma) according to the manufacturer's instructions. Cell culture supernatants and cell lysates were collected and assessed for LDH content. The percentage of LDH release was calculated by taking the ratio of LDH in supernatants of experimental wells to the LDH in control supernantants plus cells lysates times 100 .

\section{Statistical analysis}

Data are expressed as mean (SE) of $\mathrm{n}$ experiments. In concentration-response experiments the - log inhibitory concentration $50 \% \quad\left(\mathrm{IC}_{50}\right)$ was calculated by non-linear regression to express compound potency (GraphPad Software Inc, San Diego, USA). Statistical analysis was carried out by analysis of variance followed by appropriate post hoc tests including Bonferroni correction. Significance was accepted as $\mathrm{p}<0.05$.

\begin{tabular}{|lll|}
\hline Control & $\square$ ROF (1 $\mu \mathrm{M})$ & $\square$ H89 $(5 \mu \mathrm{M})$ \\
$\square$ EGF (25 ng/ml) & $\square$ ROF+EGF & $\square$ H89+ROF+EGF \\
\hline
\end{tabular}

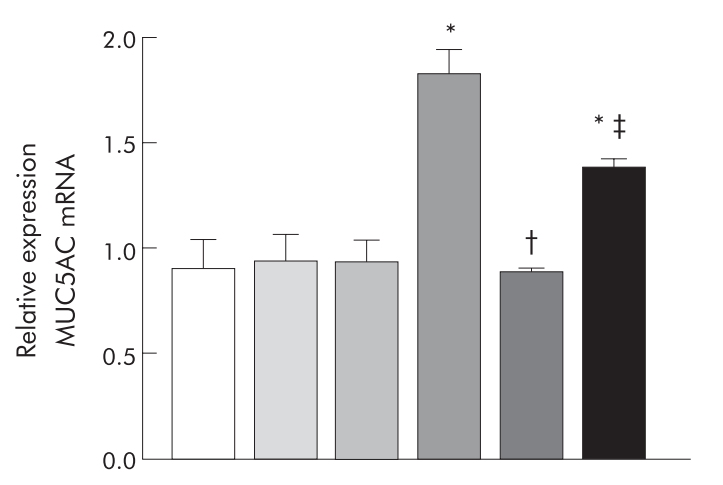

\begin{tabular}{|c|c|c|}
\hline$\square$ Control & $\square$ FORS $(3 \mu M)$ & $\square$ BIMPS $(10 \mu \mathrm{M})$ \\
\hline$\square$ db-cAMP $(100 \mu \mathrm{M})$ & EGF $(25 \mathrm{ng} / \mathrm{ml})$ & FORS+EGF \\
\hline BIMPS+EGF & $\mathrm{db}-\mathrm{cAMP}+\mathrm{EGF}$ & \\
\hline
\end{tabular}

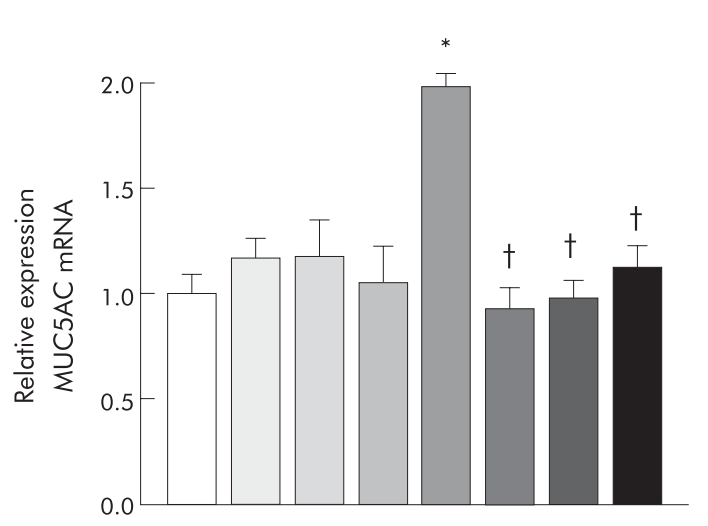

RESULTS

\section{Cytotoxicity studies and drug vehicle effects}

None of the compounds at their maximal concentrations used showed any significant cytotoxicity (values for LDH release were below 5\%).

DMSO $(0.1 \% \mathrm{v} / \mathrm{v})$ did not alter the MUC5AC mRNA and protein expression in the absence and presence of EGF $25 \mathrm{ng} /$ $\mathrm{ml}$ (fig 1)

\section{Effect of PDE4 inhibition on EGF induced MUC5AC} expression and EGFR signalling cascade in A549 cells EGF $(25 \mathrm{ng} / \mathrm{ml} ; 24$ hours incubation) increased MUC5AC gene expression and protein production in A549 cells (fig 1). This finding was confirmed by immunocytochemical staining for MUC5AC (not shown). The dependency of this response on the tyrosine kinase activity of the EGFR was confirmed by inhibition of the EGF induced increase in MUC5AC mRNA
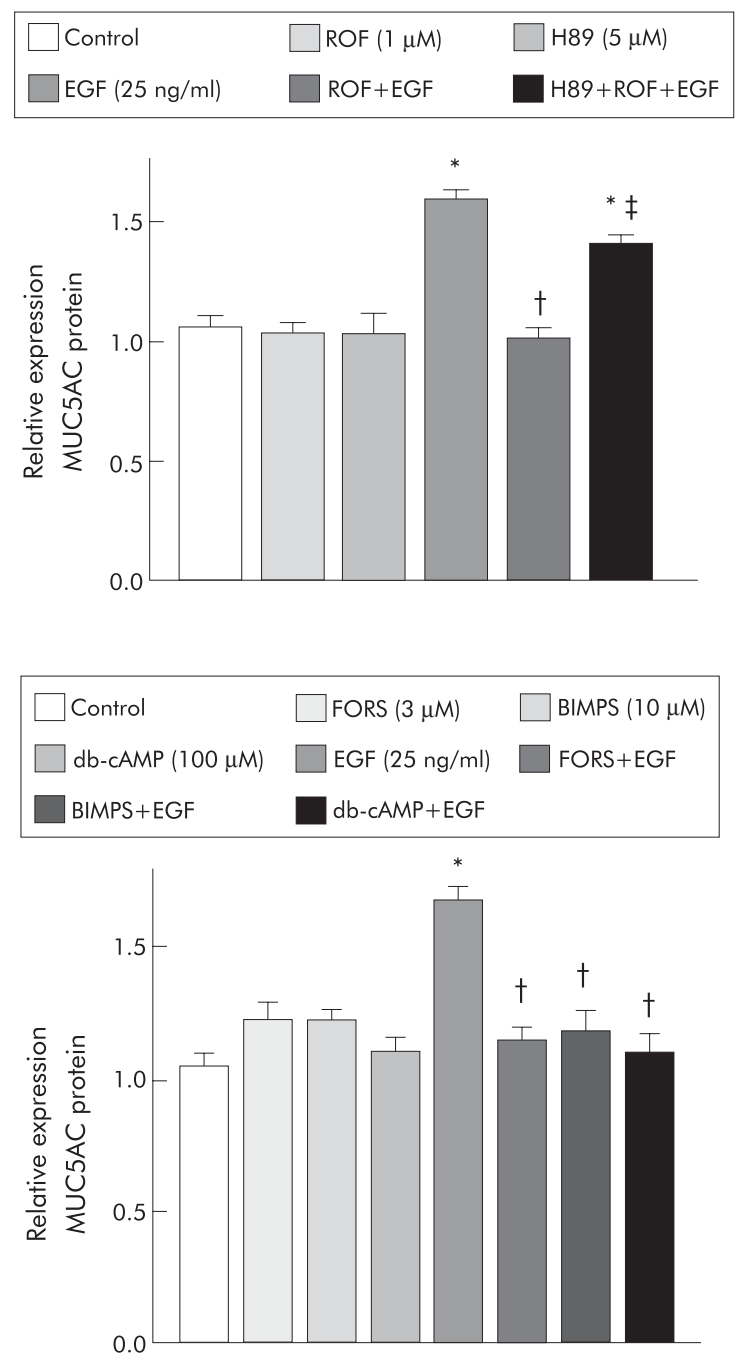

Figure 6 Relative quantitation of MUC5AC mRNA and protein levels in A549 cells unstimulated (control) or stimulated with epidermal growth factor (EGF) in the absence or presence of roflumilast (upper panels) or drugs acting through the CAMP/PKA pathway (lower panels). Roflumilast (ROF; $1 \mu M$ ) had no direct effect on MUC5AC expression but abolished the EGF $(25 \mathrm{ng} / \mathrm{ml})$ induced increase in MUC5AC expression. This inhibitory effect of roflumilast was reversed in the presence of $\mathrm{H} 89(5 \mu \mathrm{M})$, a PKA inhibitor. To turther explore the influence of the CAMP/PKA pathway in the EGF induced enhancement of MUC5AC expression, the activity of forskolin (FORS; $3 \mu \mathrm{M}$ ), a direct activator of adenylyl cyclase, Sp-5,6-DCl-cBIMPS (BIMPS; $10 \mu \mathrm{M})$, a direct activator of PKA, and db-cAMP $(100 \mu \mathrm{M})$, a cell permeable analogue of cAMP, were tested. None of these compounds altered the basal MUC5AC expression at the concentrations tested, but each inhibited the EGF induced overexpression of MUC5AC mRNA and protein. MUC5AC mRNA was determined using real-time RT-PCR by the $\Delta \Delta C_{t}$ method; columns show the fold increase in expression of MUC5AC relative to GAPDH values as mean (SE) of the $2^{-\Delta \Lambda C t}$ values of three independent experiments. MUC5AC protein was determined by enzyme linked immunosorbent assay (ELISA); columns show the fold increase from control levels as mean (SE) values of three to six independent experiments. ${ }^{*} p<0.05 v$ control; $\neq p<0.05 v$ EGF alone. 


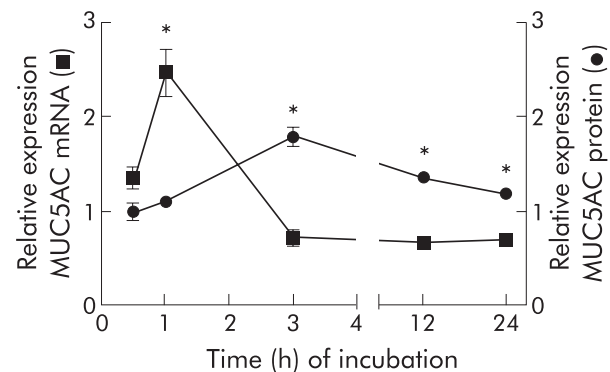

Figure 7 Time course of the relative expression of MUC5AC mRNA and protein in human isolated bronchus. The peak expression for MUC5AC mRNA was observed 1 hour after stimulation with EGF, thus preceding the peak expression of MUC5AC protein at 3 hours. MUC5AC mRNA was determined using real time RT-PCR by the $\Delta \Delta C_{t}$ method; points show the fold increase in expression of MUC5AC relative to GAPDH values as mean (SE) of the $2^{-\Delta \Delta C t}$ values. MUC5AC protein was determined in tissue by ELISA; points are mean (SE) of bronchial tissues. Data were obtained from three to five different patients. ${ }^{*} \mathrm{p}<0.05 v$ basal values.

and protein in the presence of two different selective inhibitors of EGFR tyrosine kinase (tyrphostin A46 and AGl478, fig 1). ${ }^{3} 1822$

Roflumilast ( $1 \mu \mathrm{M})$, a PDE4 inhibitor, did not change basal MUC5AC expression but prevented the increase in MUC5AC mRNA and protein production in response to EGF (fig l). The relationship between the suppression of EGF induced MUC5AC expression and the PDE4 inhibition was further explored by examining the inhibitory effects of other structurally unrelated PDE4 inhibitors and by exploring their concentration dependency. The increase in MUC5AC mRNA and protein by EGF was inhibited in a concentration-related fashion by pretreatment of cells with the PDE4 inhibitors roflumilast, cilomilast, and rolipram (fig 2). The rank order of potencies $\left(-\log \mathrm{IC}_{50}\right.$ values) was roflumilast $(7.59(0.27))>$ rolipram $(6.66(0.26))>$ cilomilast $(5.58(0.23))$ for MUC5AC mRNA, and roflumilast $(7.37(0.12))>$ rolipram $(6.17$ $(0.16))>$ cilomilast $(5.27(0.10))$ for MUC5AC protein. A fully active concentration of roflumilast $(1 \mu \mathrm{M})$ was selected for additional experiments.

Addition of EGF ( $25 \mathrm{ng} / \mathrm{ml} ; 24$ hours incubation) to A549 cells resulted in the phosphorylation of the tyrosine residues of different intracellular proteins and the augmented expression of the EGFR, as shown by Western blot analysis of cell lysates with the corresponding specific antibodies (fig 3). Expression of phospho-p38 MAPK and phospho-p44/ 42 MAPK reached peak values after 15 minutes of exposure to EGF $(25 \mathrm{ng} / \mathrm{ml})$. Treatment with roflumilast $(1 \mu \mathrm{M})$ abolished these EGF induced responses (fig 3). The functional requirement for p38 MAPK and for p44/42 MAPK in the EGF induced augmentation of MUC5AC mRNA was shown by using their respective selective inhibitors SB202190 and PD98059 (fig 4). ${ }^{31823}$

\section{Relationship between inhibition of EGF induced MUC5AC expression by PDE4 inhibitors and the CAMP/PKA pathway in A549 cells}

We then examined whether the inhibitory effect of roflumilast on the overexpression of MUC5AC promoted by EGF was related to its ability to inhibit PDE4, thus increasing CAMP and subsequently activating PKA. EGF alone failed to alter the cellular content of cAMP significantly. Roflumilast ( $1 \mu \mathrm{M})$ produced an early (peak at 5 minutes) and transient increase in the cAMP content of A549 cells (fig 5). The inhibitory effect of roflumilast on the EGF induced MUC5AC response was reversed in the presence of $\mathrm{H}-89(5 \mu \mathrm{M})$, an inhibitor of $\mathrm{PKA}^{24}$ thus reinforcing the view of a mechanism
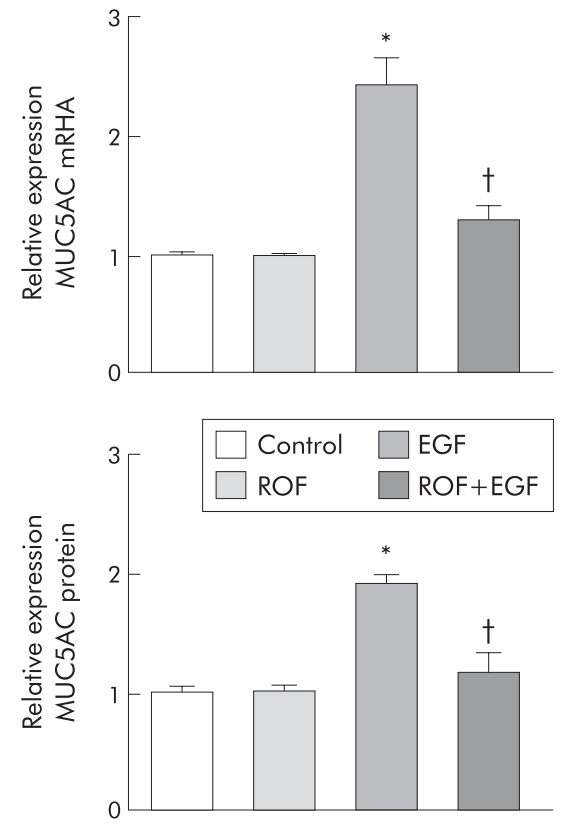

Figure 8 Relative quantitation of MUC5AC mRNA (upper panel) and protein levels (middle panel) in human bronchus unstimulated (control) or stimulated with epidermal growth factor (EGF; $25 \mathrm{ng} / \mathrm{ml}$ ) in the absence or presence of roflumilast (ROF, $1 \mu \mathrm{M})$. Exposure time was 1 hour for MUC5AC mRNA determination and 3 hours for MUC5AC protein measurements. The EGF induced increase in MUC5AC expression was abolished by roflumilast. MUC5AC mRNA was determined using real time RT-PCR by the $\Delta \Delta C_{t}$ method; columns show the fold increase in expression of MUC5AC relative to GAPDH values as mean (SE) of the $2^{-\Delta \Delta C t}$ values of three independent experiments. MUC5AC protein was determined by enzyme linked immunosorbent assay (ELISA); columns show the fold increase from control levels as mean (SE) values of three independent experiments. ${ }^{*} p<0.05 v$ control; $t p<0.05 v$ EGF. The lower panel shows MUC5AC protein in human bronchus determined by Western blotting with anti-MUC5AC

monoclonal antibody. A representative experiment of three independent experiments is shown for the same experimental groups (C, control; $E$, EGF; $R+E$, roflumilast+EGF). Molecular weight marker is shown on the left $(213 \mathrm{kDa})$. The immunostained band of high molecular weight was augmented in EGF exposed samples and markedly diminished in roflumilast treated preparations.

of action for roflumilast related to the cAMP/PKA pathway (fig 6).

To establish the ability of the cAMP/PKA pathway to interfere with the EGF induced overexpression of MUC5AC we showed that forskolin $(10 \mu \mathrm{M})$, a direct activator of 

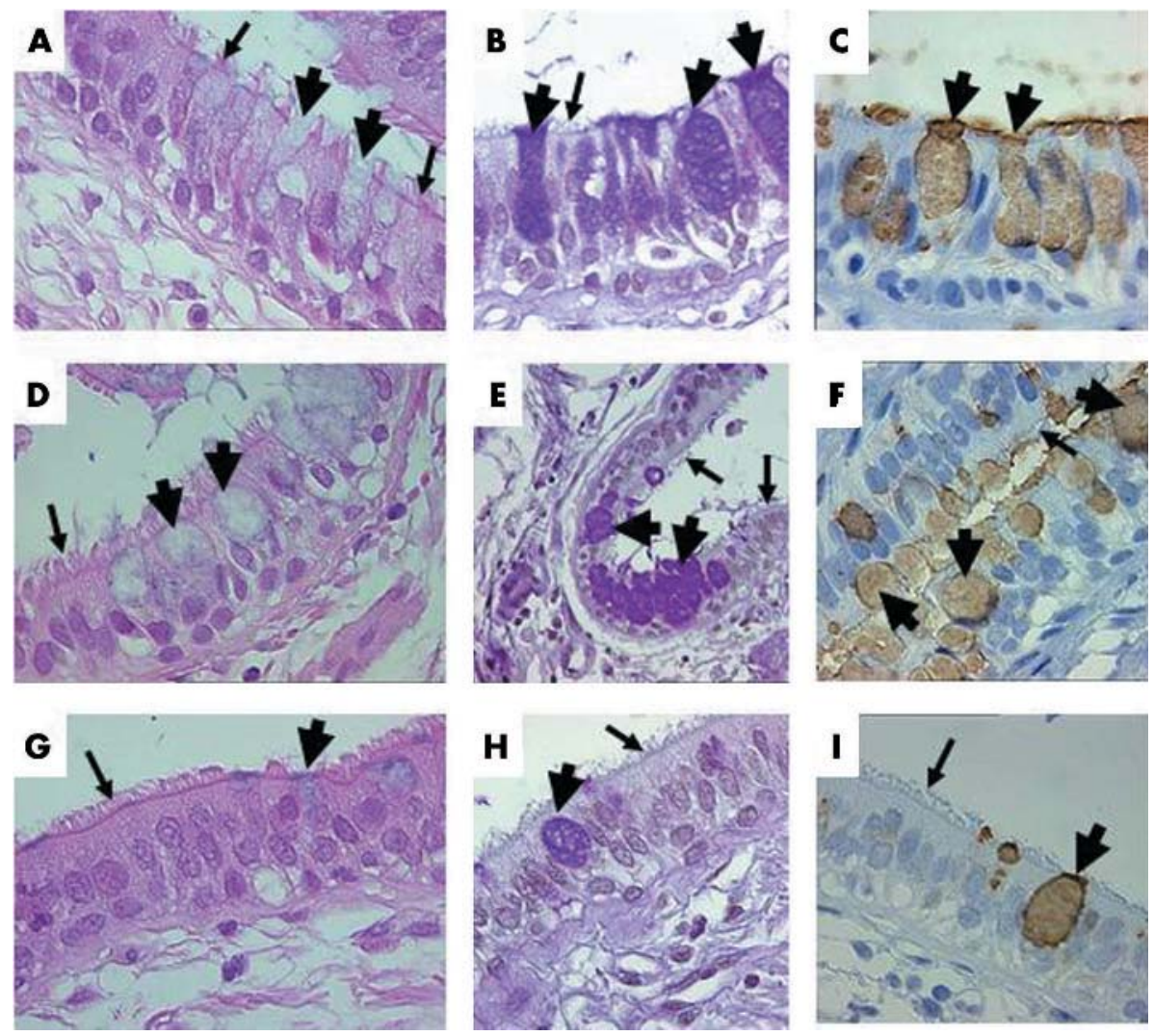

Figure 9 Photomicrographs of representative histological sections from human bronchial tissue unstimulated (A, B, C) or stimulated with EGF (25 ng/ $\mathrm{ml})$ in the absence $(D, E, F)$ or presence $(G, H, I)$ of roflumilast $(1 \mu M)$. Sections show haematoxylin-eosin $(A, D, G)$ or periodic acid-Schiff (PAS; $B, E, H)$ staining or immunohistochemical staining of MUC5AC $(C, F, I)$. Mucin stores in goblet cells appear as purple staining (B, E, H). MUC5AC immunoreactivity was observed as brown staining in goblet cells (C, F, I). Ciliated cells showed no staining for MUC5AC. The sections demonstrate increased PAS and MUC5AC staining in the tissues exposed to EGF, and roflumilast prevented this augmentation. Original magnification $\times 400$ (except panel E: $\times 250$ ). Goblet cells are indicated by thick arrows and ciliated cells as thin arrows.

adenylyl cyclase, ${ }^{24} \mathrm{db}$-cAMP $(100 \mu \mathrm{M})$, a membrane permeable analogue of CAMP, ${ }^{25}$ and Sp-5,6-DCl-cBIMPS (100 $\left.\mu \mathrm{M}\right)$, an activator of $\mathrm{PKA}^{26}$ - while not altering the control level of MUC5AC expression-were impeding the enhanced expression of MUC5AC elicited by EGF (fig 6).

\section{Effect of PDE4 inhibition on EGF induced MUC5AC expression in human isolated bronchus}

Since A549 cells are a cancer cell line, the results obtained with these cells may differ from responses of normal airway epithelium. Additional experiments were therefore performed using human isolated bronchial tissue. In this preparation EGF $(25 \mathrm{ng} / \mathrm{ml})$ augmented the MUC5AC mRNA and protein expression with peak values reached at 1 hour and 3 hours after EGF exposure, respectively (fig 7). These effects of EGF were suppressed in the presence of tyrphostin A46 (not shown). Roflumilast ( $1 \mu \mathrm{M})$ prevented the EGF induced overexpression of MUC5AC (fig 8).

Immunohistochemistry experiments showed that MUC5AC immunoreactivity was localised in goblet cells that were stained with PAS (fig 9). The MUC5AC positive staining in airway epithelium was increased in EGF exposed preparations, and this augmentation was reduced in roflumilast treated tissues.

\section{DISCUSSION}

In this study we found that PDE4 inhibition abolished the EGF induced augmentation of MUC5AC mRNA and protein expression in cultured human airway epithelial cells and in human bronchial tissue in vitro. To our knowledge, this is the first report of a direct inhibitory effect on mucin production of PDE4 inhibitors, a new class of drugs with potential therapeutic interest in the treatment of COPD and asthmadiseases in which mucus hypersecretion is considered pathologically relevant.

\section{EGF activates EGFR signalling cascade and MUC5AC expression in A549 cells}

The EGFR signalling cascade is important for regulating MUC5AC mucin gene expression and protein production by airway epithelial cells, ${ }^{6}$ and both the EGFR and the MUC5AC expression are upregulated in chronic airway diseases such as asthma and COPD. ${ }^{13} 7$ The EGFR signalling pathway translates into increased MUC5AC expression, the activation produced by many different stimuli including oxidative stress, neutrophil elastase, tobacco smoke, bacterial and viral products, and inflammatory cytokines. ${ }^{17}{ }^{18}{ }^{27}$ In this study we have selected EGF, an endogenous ligand of the EGFR, as a direct activator of this pathway based on previous studies in cultured human airway epithelial NCI-H292 cells. ${ }^{6}{ }^{18}$

We confirmed that A549 cells have a constitutive expression of $\mathrm{EGFR}^{28}$ as shown by the faint band observed in Western blot analysis with anti-EGFR mAb in the control group (fig 3). The activation of the EGFR system results in an increase of about twofold in MUC5AC mRNA and protein expression as shown by ELISA data obtained after 24 hours of incubation with EGF. Immunocytochemistry of A549 cells confirmed this finding. The increase in MUC5AC mRNA and protein at 24 hours is within the time dependency shown in cultured human airway epithelial cells for MUC5AC 
production elicited with various stimuli activating EGFR including EGF. ${ }^{6}{ }^{17} 18$

Consistent with the notion that the overexpression of MUC5AC is the consequence of the activation of the EGFR signalling cascade, we also found that preincubation with EGFR tyrosine kinase inhibitors prevented the EGF induced augmentation of the MUC5AC mRNA expression and protein production (fig 1). EGF therefore increases the proteintyrosine kinase activity of its receptor and thereby activates other kinase cascades such as MAPKs including p38 and p44/ 42 MAPKs. $^{29}$ As expected, we found an early activation of p38- and p44/42-MAPK as well as phosphorylation of tyrosine residues of different cell proteins and upregulation of the EGFR after exposure to EGF for 24 hours (fig 3). Furthermore, inhibition of p38-and p44/42-MAPKs with the selective inhibitors SB20202190 and PD98059 abrogated the EGF induced MUC5AC mRNA expression.

\section{PDE4 inhibitors suppress the EGF induced MUC5AC expression in A549 cells by activating the CAMP/PKA pathway}

There is evidence to indicate that the functioning of the cAMP/PKA pathway is linked with that of the ERK/MAPK pathway. Thus, agents that increase the intracellular cAMP concentration block growth factor stimulated ERK activation in a number of cell types by inhibiting the activation of Raf proteins. ${ }^{13}{ }^{30}$ In fact, PDE4 isoenzymes may provide a pivotal point for integrating CAMP and ERK signal transduction in cells. ${ }^{31}$ The known relevance of PDE4 isoenzyme activity in the regulation of cAMP levels in human airway epithelial cells, including A549 cells, ${ }^{11}{ }^{12}$ prompted us to investigate the effects of monoselective PDE4 inhibitors on the EGF induced MUC5AC expression and related events occurring in A549 cells.

We found that three different structurally unrelated PDE4 inhibitors - the archetypal PDE4 inhibitor rolipram and the second generation PDE4 inhibitors cilomilast and roflumilast-produced concentration dependent inhibitions of the EGF induced MUC5AC mRNA and protein expression. The potency order of their activities (expressed as $-\log \mathrm{IC}_{50}$ values) was roflumilast $(\sim 7.5)>\operatorname{rolipram}(\sim 6.5)>$ cilomilast $(\sim 5.5)$. These differences in potencies are consistent with results obtained in other in vitro human cell systems, yet variation may exist depending on the stimulus and the cell type studied. ${ }^{32}$ Since roflumilast ( $\left.1 \mu \mathrm{M}\right)$ suppressed both MUC5AC mRNA and protein production in response to EGF, this concentration was selected for further studies.

The inhibitory action of roflumilast appears to be exerted at different levels of the EGFR signalling cascade. Thus, we showed that roflumilast ( $1 \mu \mathrm{M}$ ) markedly inhibited the early phospho-p38 MAPK expression as well as the phosphorylation of tyrosine residues of proteins and the overexpression of EGFR in response to EGF stimulation measured at 24 hours EGF exposure.

The inhibitory effects of roflumilast on the EGFR cascade events leading to enhanced MUC5AC expression are probably related to the activation of the CAMP/PKA pathway since this selective PDE4 inhibitor elicited a transient early increase in cAMP levels in A549 cells, and its inhibitory effects on MUC5AC expression were reversed by preincubation with $\mathrm{H}-$ 89, an inhibitor of PKA activity. ${ }^{24}$ Furthermore, forskolin (a direct activator of adenylyl cyclase), ${ }^{24} \mathrm{db}$-cAMP (a membrane permeant analogue of cAMP), ${ }^{25}$ and Sp-5,6-DCl-cBIMPS (a specific activator of PKA) ${ }^{26}$ prevented the enhanced expression of MUC5AC elicited by EGF (fig 6), thus supporting the notion that the activation of the cAMP/PKA pathway is effective in exerting an inhibitory influence on the EGFR cascade leading to MUC5AC expression in A549 cells.

\section{PDE4 inhibition attenuates EGF induced MUC5AC} expression in human airways in vitro

The inhibitory effects resulting from PDE4 inhibition with roflumilast in cultured A549 cells may not necessarily be representative of the responses of the epithelial cells in the human airways. MUC5AC expression was therefore also examined in human isolated bronchus, a preparation that has previously been shown to have a basal secretion of mucin MUC5AC produced principally by goblet cells. ${ }^{16}$ In the human airways in vitro, MUC5AC mRNA expression reached a peak at 1 hour after stimulation with EGF, while peak MUC5AC protein production in tissue and medium was observed at 3 hours (fig 7). This represents faster kinetics of MUC5AC expression than in cultured A549 cells, but we have not investigated the reason for this difference. Pretreatment with roflumilast $(1 \mu \mathrm{M})$ markedly inhibited this augmented expression of MUC5AC induced by EGF activation, indicating that the direct inhibitory effects produced by this PDE4 inhibitor in cultured A549 cells are reproducible in intact airway epithelial cells. Immunohistochemical analysis of human bronchial tissues confirmed that EGF exposure resulted in an augmented expression of MUC5AC positive stained cells in airway epithelium and treatment with roflumilast effectively prevented this EGF induced overexpression of MUC5AC (fig 9).

In summary, the results of this study indicate that putative PDE4 inhibitors, in addition to their established inhibitory effects on the airway inflammatory cells, ${ }^{90}$ may also exert direct effects on human airway epithelial cells inhibiting the MUC5AC expression that follows the activation of the EGFR signalling cascade. These findings may be of added value to results from recent phase II/III clinical trials which suggest a therapeutic benefit for PDE4 inhibitors in mucus hypersecretory diseases such as COPD and asthma. ${ }^{8}$

\section{ACKNOWLEDGEMENTS}

The authors are indebted to the teams of the Services of Thoracic Surgery and Pathology of the University Clinic Hospital and 'La Fe' University Hospital of Valencia (Spain) for making the human lung tissue available to us, and to Altana Pharma for the gift of phosphodiesterase 4 inhibitors. The technical assistance of Pedro Santamaria and Dora Martí is also gratefully acknowledged.

\section{Authors' affiliations}

M Mata, B Sarriá, A Buenestado, J Cortiio, E J Morcillo, Department of Pharmacology, Faculty of Medicine, University of Valencia, Valencia, Spain

J Cortiio, Research Foundation, University General Hospital, University of Valencia, Valencia, Spain

M Cerdá, Department of Pathology, Faculty of Medicine, University of Valencia, Valencia, Spain

This work was supported by grants SAF2002-04667 and SAF200307206-C02-01 from CICYT (Ministry of Science and Technology, Spanish Government) and Research Groups-03/166 funding from Regional Government (Generalitat Valenciana).

\section{REFERENCES}

1 Takeyama K, Fahy JV, Nadel JA. Relationship of epidermal growth factor receptors to goblet cell production in human bronchi. Am J Respir Crit Care Med 2001;163:511-6.

2 Leikauf GD, Borchers MT, Prows DR, et al. Mucin apoprotein expression in COPD. Chest 2002;121:166-82S.

3 Gensch E, Gallup M, Sucher A, et al. Tobacco smoke control of mucin production in lung cells requires oxygen radicals AP-1 and JNK. J Biol Chem 2004;279.39085-93.

4 Groneberg DA, Eynott PR, Lim S, et al. Expression of respiratory mucins in fatal status asthmaticus and mild asthma. Histopathology 2002;40:367-73.

5 Kirkham S, Sheehan JK, Knight D, et al. Heterogeneity of airway mucus: variations in the amounts and glycoforms of the major oligomeric mucins MUC5AC and MUC5B. Biochem J 2002;361:537-46.

6 Takeyama K, Dabbagh K, Lee HM, et al. Epidermal growth factor system regulates mucin production in airways. Proc Natl Acad Sci USA 1999;96:3081-6. 
7 Polosa R, Puddicombe SM, Krishna MT, et al. Expression of c-erbB receptors and ligands in the bronchial epithelium of asthmatic subjects. J Allergy Clin Immunol 2002;109:75-81.

8 Giembycz MA. Development status of second generation PDE4 inhibitors for asthma and COPD: the story so far. Monaldi Arch Chest Dis 2002;57:48-64.

9 Kanehiro A, Ikemura T, Makela MJ, et al. Inhibition of phosphodiesterase 4 attenuates airway hyperresponsiveness and airway inflammation in a model of secondary allergen challenge. Am J Respir Crit Care Med 2001;163:173-84.

10 Toward TJ, Broadley KJ. Goblet cell hyperplasia, airway function, and leukocyte infiltration after chronic lipopolysaccharide exposure in conscious guinea pigs: effects of rolipram and dexamethasone. J Pharmacol Exp Ther 2002;302:814-21.

11 Dent G, White SR, Tenor H, et al. Cyclic nucleotide phosphodiesterase in human bronchial epithelial cells: characterization of isoenzymes and functional effects of PDE inhibitors. Pulm Pharmacol Ther 1998;11:47-56.

12 Fuhrmann M, Jahn H-U, Seybold J, et al. Identification and function of cyclic nucleotide phosphodiesterase isoenzymes in airway epithelial cells. Am J Respir Cell Mol Biol 1999;20:292-302.

13 Sevetson BR, Kong X, Lawrence JC Jr. Increasing CAMP attenuates activation of mitogen-activated protein kinase. Proc Natl Acad Sci USA 1993;90:10305-9.

14 Berger JT, Voynow JA, Peters KW, et al. Respiratory carcinoma cell lines. MUC genes and glycoconjugates. Am J Respir Cell Mol Biol 1999:20:500-10.

15 Sarria B, Naline E, Zhang $Y$, et al. Muscarinic $M_{2}$ receptors in acetylcholineisoproterenol functional antagonism in human isolated bronchus. Am J Physiol 2002;283:L1125-32.

16 Labat C, Bara J, Gascard JP, et al. MI/MUC5AC mucin released by human airways in vitro. Eur Respir J 1999;14:390-5.

17 Takeyama K, Dabbagh K, Shim JJ, et al. Oxidative stress causes mucin synthesis via transactivation of epidermal growth factor receptor: role of neutrophils. J Immunol 2000;164:1546-52.

18 Khori K, Ueki IF, Shim J-J, et al. Pseudomona aeruginosa induces MUC5AC production via epidermal growth factor receptor. Eur Respir $J$ 2002;20:1263-70.

19 Mata A, Ruíz A, Cerdá M, et al. Oral N-acetylcysteine reduces bleomycininduced lung damage and mucin Muc5ac expression in rats. Eur Respir J 2003;22:900-5.

20 Bradford M. A rapid and sensitive method for the quantitation of microgram quantities of protein utilizing the principle of protein-dye binding. Anal Biochem 1976;72:248-54.
21 Cortiio J, Villagrasa V Pons R, et al. Bronchodilator and anti-inflammatory activities of glaucine: in vitro studies in human airway smooth muscle and polymorphonuclear leukocytes. Br J Pharmacol 1999;127:1641-51.

22 Crump CM, Williams JL, Stephens DJ, et al. Inhibition of the interaction between tyrosine-based motifs and the medium chain subunit of the AP-2 adaptor complex by specific tyrphostins. J Biol Chem 1998;273:28073-7.

23 Kawaguchi M, Kokubu F, Matsukura S, et al. Induction of C-X-C chemokines, growth-related oncogene $\alpha$ expression, and epithelial cell-derived neutrophilactivating protein-78 by ML-1 (interleukin-17F) involves activation of raf1mitogen-activated protein kinase kinase-extracellular signal-regulated kinase 1/2 pathway. J Pharmacol Exp Ther 2003;307:1213-20.

24 Chiïiwa T, Mishima A, Hagiwara M, et al. Inhibition of forskolin-induced outgrowth and portein phosphorylation by a newly synthesized selective inhibitor of cyclic AMP-dependent protein kinase, N-[2-(p-

bromocinnamylamino)ethyl]-5-isoquinolinesulfonamide ( $\mathrm{H}-89)$, of PC 12D Pheochromocytoma cells. J Biol Chem 1990;265:5267-72.

25 Pedrosa R, Gomes P, Soares-da-Silva P. Distinct signalling cascades downstream to $G_{5} \alpha$ coupled dopamine $D_{1}$-like NHE3 inhibition in rat and opossum renal epithelial cells. Cell Physiol Biochem 2004;14:91-100.

26 Sandberg M, Butt E, Nolte C, et al. Characterization of Sp-5,6-dichloro-1beta-D-ribofuranosylbenzimidazole-3', 5' -monophosphorothioate (Sp-5,6DCl-cBiMPS) as a potent and specific activator of cyclic-AMP-dependent protein kinase in cell extracts and intact cells. Biochem J 1991;279:521-7.

27 Basbaum C, Li D, Gensch E, et al. Mechanisms by which Gram-positive bacteria and tobacco smoke stimulate mucin induction through the epidermal growth factor receptor (EGFR). In: Chadwick DJ, Goode JA, eds. Mucus hypersecretion in respiratory disease. Chichester: John Wiley \& Sons, 2002:171-6.

28 Hauck CR, Sieg DJ, Hsia DA, et al. Inhibition of focal adhesion kinase expression or activity disrupts epidermal growth factor-stimulated signaling promoting the migration of invasive human carcinoma cells. Cancer Res 2001;61:7079-90.

29 Wetzker R, Böhmer F-D. Transactivation joins multiple tracks to the ERK/ MAPK cascade. Nature Rev Mol Cell Biol 2003:4:651-7.

30 Piiper A, Gebhardt R, Kronenberger B, et al. Pertussis toxin inhibits cholecystokinin- and epidermal growth factor-induced mitogen-activated protein kinase activation by disinhibition of the CAMP signaling pathway and inhibition of c-Raf-1. Mol Pharmacol 2000:58:608-13.

31 Baillie GS, MacKenzie SJ, McPhee I, et al. Sub-family selective actions in the ability of Erk2 MAP kinase to phosphorylate and regulate the activity of PDE4 cyclic AMP-specific phosphodiesterases. Br J Pharmacol 2000;131:81 1-9.

32 Hatzelmann A, Schudt C. Anti-inflammatory and immunomodulatory potential of the novel PDE4 inhibitor roflumilast in vitro. J Pharmacol Exp Ther 2001;297:267-79.

\section{Correction}

It has been brought to our attention that there is an error in figure 3 on page ii55 of the Pleural Disease Guideline available at www.brit-thoracic.org.uk/docs/PleuralDiseaseChestDrain/ pdf. Below is a corrected diagram illustrating the "safe triangle" for a chest drain. The publishers apologise for this error.

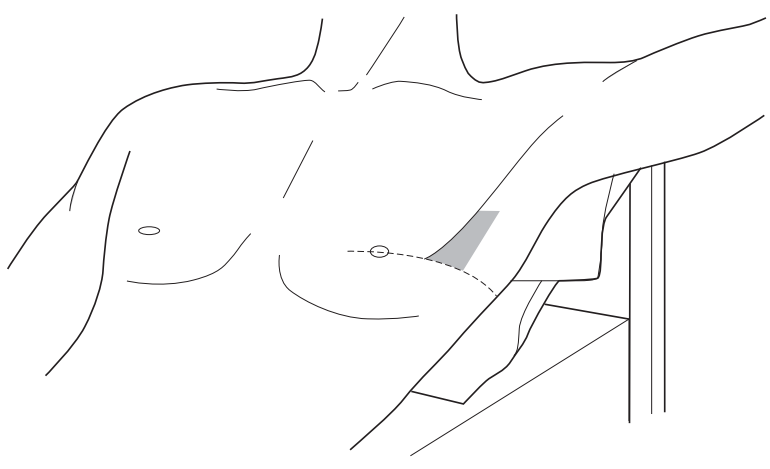

